\title{
Haematological and tissue abnormalities in chicks caused by acute and subclinical folate deficiency
}

\author{
By M. H. MAXWELL, C. C. WHITEHEAD* AND J. ARMSTRONG \\ AFRC Institute for Grassland and Animal Production, Poultry Division, Roslin, \\ Midlothian EH25 9PS
}

(Received 24 February 1987 - Accepted 24 July 1987)

\begin{abstract}
1. Haematological, histological and ultrastructural findings in young chicks fed on a purified diet severely deficient in folate are reported.

2. Growth of the birds was greatly depressed and they had a macrocytic anaemia. Other haematological changes included abnormal nuclear formations in erythrocytes, numerous mitoses and hypersegmented granulocytes.

3. Megaloblasts were observed in bone marrow and their fine structure is described for the first time in an avian species.

4. Morphological changes occurred also in the liver. The parenchyma had damaged sinusoidal endothelium, inflammatory cells and no glycogen. Mitochondria were damaged and many were associated with unusual crystalline structures.

5. Chickens fed on a semi-purified diet of low folate content showed no growth depression or clinical signs of deficiency but had abnormal haematological values and morphological changes that resembled those seen in birds fed on the purified diet.

6. These abnormalities responded to dietary supplements of pteroylmonoglutamic acid in a dose-related manner and may be useful in diagnosing subclinical folate deficiency.
\end{abstract}

The assessment of vitamin status in poultry flocks depends on specific criteria for individual vitamins being available. Such criteria are largely lacking in the case of folic acid. Clinical signs of folic acid deficiency in young chickens are very unspecific but include lethargy, growth depression and mortality. Specific biochemical criteria of status have not yet been established, but haematological abnormalities in folate-deficient chicks have been reported. An anaemia described as macrocytic and hyperchromic has been observed by Hogan \& Parrott (1940) although Campbell et al. (1945) have stated that in some cases it can be hypochromic. The anaemia has been characterized by decreases in haemoglobin $(\mathrm{Hb})$ concentrations and numbers of erythrocytes, leucocytes and thrombocytes, together with increases in erythrocyte size and the proportion of heterophils relative to lymphocytes.

The present report describes the results of a more detailed investigation at the microscopic and ultrastructural level of haematological and other tissue abnormalities associated with folate deficiency in young chicks. One experiment was carried out on severely deficient birds to characterize the range of abnormalities and to assess their specificity for folic acid deficiency. Another studied the changes associated with a lesssevere deficiency and the response to graded additions of pteroylmonoglutamic acid to the diet.

\section{MATERIALS AND METHODS}

\section{Procedure}

Male broiler chicks were housed in compartments of electrically-heated brooders at 1-d-old and given free access to feed and water. In Expt 1, groups of six chicks were each fed on the purified folate-deficient diet (diet A) alone or supplemented with $50 \mathrm{mg}$ pteroylmonoglutamic acid $/ \mathrm{kg}$. At $21 \mathrm{~d}$ of age, individual blood samples were taken by heart

\footnotetext{
* For reprints.
} 
Table 1. Composition of experimental diets $(\mathrm{g} / \mathrm{kg})$

\begin{tabular}{lrr}
\hline Basal diet... & A & B \\
\hline Casein (low-vitamin) & 186 & 150 \\
Gelatin & 94 & 60 \\
Isolated soya-bean protein & & 150 \\
Meat-and-bone meal & 566 & 507 \\
Starch & 20 & 50 \\
Maize oil & 75 & 50 \\
Cellulose & 20 & 17 \\
Limestone flour & 20 & 4 \\
Dicalcium phosphate & 4 & $4 \cdot 5$ \\
Salt & & $1 \cdot 5$ \\
DL-Methionine & 10 & 10 \\
L-Cystine & \\
Vitamin and mineral supplement* &
\end{tabular}

* Provided $(\mathrm{mg} / \mathrm{kg}$ diet) : copper 3.5, iodide $0 \cdot 4$, iron 80, magnesium 300, manganese 100 , zinc 50 , sodium molybdate 9 , sodium selenite 0.6 , potassium chloride $8 \mathrm{~g}$, retinol 2 , cholecalciferol $20 \mu \mathrm{g}, \alpha$-tocopherol 17 , menadione $1 \cdot 3$, thiamin 5 , riboflavin 4 , nicotinic acid 28 , pantothenic acid 10 , pyridoxine 8 , cyanocobalamin $0 \cdot 01$, biotin $0 \cdot 3$, choline chloride $1.5 \mathrm{~g}$.

puncture; part of each sample was separated into serum or plasma using heparin as anticoagulant. The birds were killed by cervical dislocation and various tissues were taken for microscopic examinations.

In Expt 2, a semi-purified diet (diet B) was given to test responses to folate under different nutritional conditions. The basal diet was thought to contain relatively low amounts of folate, although more than diet $A$, and it was given alone or supplemented with 2,4 or $20 \mathrm{mg}$ pteroylmonoglutamic acid/ $\mathrm{kg}$ to replicate groups of five to six chicks. Blood and tissue samples were taken as described previously at $28 \mathrm{~d}$. The compositions of the basal diets are given in Table 1.

\section{Methods}

Folate assay. Folate concentrations were measured in pooled plasma and serum from each group. The assay involved competitive binding with $\left[{ }^{3} \mathrm{H}\right]$ pteroylmonoglutamic acid (Amersham International plc, Amersham, Bucks) on lyophilized bovine milk $\beta$-lactoglobulin (Sigma Chemical Co., Poole, Dorset) using the procedures described by Waxman \& Schreiber (1980).

Haematology. Blood samples for the haematological tests were mixed with the anticoagulant dipotassium salt of EDTA $(1.5 \mathrm{mg} / \mathrm{ml}$ blood). The tests included $\mathrm{Hb}$, measured by the cyanmethaemoglobin method, and the packed cell volume (PCV) which was determined by the microhaematocrit method. The erythrocyte $(\mathrm{Rbc})$, leucocyte (Wbc) and thrombocyte counting methods were similar to those described previously (Maxwell, 1981). The results were used to calculate mean cell volume (MCV), mean cell $\mathrm{Hb}(\mathrm{MCHb})$ and mean cell $\mathrm{Hb}$ concentration (MCHbC). Blood smears were fixed in methanol for $6 \mathrm{~min}$ and then stained in concentrated May Grunwald for 3 min and 1 in 10 Giemsa solution for $15 \mathrm{~min}$ and the Wbc differential counts were performed.

Reticulocyte counts were carried out on whole-blood samples. Blood $(50 \mu \mathrm{l})$ was mixed with $50 \mu$ l brilliant cresyl blue, prepared according to Coates \& March (1966), and the tubes were allowed to stand at room temperature for $60 \mathrm{~min}$. The reticulocytes were counted by the method of Coates \& March (1966) and were divided into five stages depending on the degree of reticulation. Bone-marrow films were made and stained by the May Grunwald-Giemsa method described previously. 
Table 2. Body-weights and serum and plasma folate concentrations in chicks fed on diets supplemented with different amounts of pteroylmonoglutamic acid

\begin{tabular}{|c|c|c|c|c|c|c|c|c|c|}
\hline \multirow{3}{*}{$\begin{array}{l}\text { Basal diet* } \ldots \\
\text { Supplemental pteroylmonoglutamic } \\
\text { acid }(\mathrm{mg} / \mathrm{kg}) \quad \ldots\end{array}$} & \multicolumn{4}{|c|}{ A } & \multicolumn{5}{|c|}{ B } \\
\hline & \multicolumn{2}{|c|}{0} & \multicolumn{2}{|c|}{50} & \multirow[t]{2}{*}{0} & \multirow[t]{2}{*}{2} & \multirow[t]{2}{*}{4} & \multirow[t]{2}{*}{20} & \multirow[b]{2}{*}{ Pooled SE } \\
\hline & Mean & SE & Mean & SE & & & & & \\
\hline \multicolumn{10}{|l|}{ Body-wt (g) at: } \\
\hline 3 weeks & 176 & 16 & 409 & 13 & - & - & - & - & - \\
\hline 4 weeks & - & - & - & - & 536 & 603 & 577 & 504 & 31 \\
\hline \multicolumn{10}{|l|}{ Folate concentration $(\mathrm{ng} / \mathrm{ml})$ in: } \\
\hline Plasma & $<1$ & & $64 \cdot 0$ & & $<1$ & $9 \cdot 3$ & $23 \cdot 5$ & $98 \cdot 4$ & \\
\hline Serum & - & & $53 \cdot 3$ & & $<1$ & $6 \cdot 5$ & $12 \cdot 0$ & $57 \cdot 0$ & \\
\hline
\end{tabular}

* For details, see Table 1.

Histopathology. Pieces of tissue were taken for histopathological examination from birds fed on diet A. The tissues included: liver, spleen, heart, kidney, small intestine and skin and all were processed in paraffin wax and $4 \mu \mathrm{m}$ thick sections were stained with haematoxylin and eosin (H and E), periodic acid Schiff (PAS) reagent and Glees and Marsland silver stain for reticulin.

Electron microscopy. Pieces of liver and bone marrow were processed for examination in an electron microscope. The liver was fixed in $0.175 \mathrm{M}$-sodium cacodylate-osmium

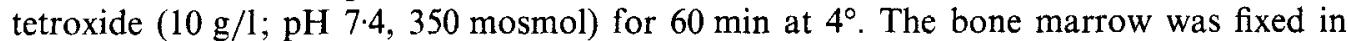
glutaraldehyde ( $60 \mathrm{~g} / 10.1 \mathrm{M}$-Millonig's phosphate buffer; $\mathrm{pH} 7 \cdot 4,900 \mathrm{mosmol})$ for $24 \mathrm{~h}$ at room temperature. The marrow blocks were then washed in $0.075 \mathrm{M}$-sodium cacodylate -0.2

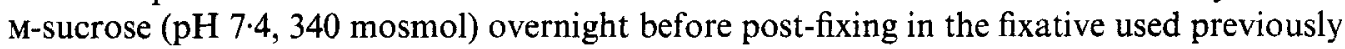
for liver. All blocks were dehydrated in ethanol, passed through Inhibisol (Maxwell, 1978) and embedded in Araldite. Thick sections $(1.0 \mu \mathrm{m})$ were stained with toluidine blue $(10 \mathrm{~g} / 1)$ in borax $(10 \mathrm{~g} / 1)$. Ultrathin sections were examined in an electron microscope.

\section{Statistical analysis}

Values were analysed using Student's $t$ test and by analysis of variance (Expt 2).

\section{RESULTS}

\section{Clinical signs of folate deficiency}

Values on the performances of the chicks are given in Table 2. Chicks fed on basal diet A had the same mean body-weights $(107 \mathrm{~g})$ as those fed on diet A supplemented with $50 \mathrm{mg}$ pteroylmonoglutamic acid $/ \mathrm{kg}$ at $7 \mathrm{~d}$ of age but growth became depressed during the $2 \mathrm{nd}$ week. The chicks were less active and some developed distorted feathering. Growth during the 3 rd week was very poor and $25 \%$ of the deficient chicks died. In a previous experiment, $90 \%$ had died before the end of the 4 th week. Visual inspection of dead birds or survivors did not reveal any obvious lesions.

Group mean body-weights at $28 \mathrm{~d}$ of age in Expt 2 were quite variable, partly as a result of the relatively large individual variation that is sometimes seen in birds fed on purified diets. It was not possible to demonstrate growth depression due to folate deficiency in birds fed on basal diet B. Mortality was very low in this experiment, there being only one death (a chick fed on the basal diet). 


\section{Blood folate concentrations}

Plasma or serum concentrations (Table 2) were too low to measure with confidence (values below $1 \mathrm{ng} / \mathrm{ml}$ ) in birds fed on both basal diets. Measurements were not carried out on serum from chicks fed on basal diet A since this showed signs of haemolysis. Folate concentrations were much higher in samples from birds fed on folate-supplemented diets and in Expt 2 values for both plasma and serum increased approximately linearly in relation to the amount of the dietary supplement. Plasma concentrations measured were consistently higher than those in serum samples.

\section{Haematology}

Haematological values are given in Table 3. Mean values for birds fed on diet A alone differed considerably from those for the corresponding controls and in most cases these differences were highly significant $(P<0.001)$. $\mathrm{Hb}, \mathrm{Rbc}$ and $\mathrm{PCV}$ were all markedly decreased in the deficient birds whereas $\mathrm{MCHb}$ and $\mathrm{MCV}$ were increased. Thrombocyte and Wbc counts were also lower and the differential count was changed, there being a considerable increase in the proportion of heterophils at the expense of lymphocytes. The reticulocyte count was also higher $(P<0.05)$ in the deficient group.

In Expt 2, where birds were fed on the semi-purified diet B, there were fewer differences between the groups. Nevertheless values for birds fed on the unsupplemented diet showed many changes relative to birds given supplemental folate that were in the same direction as those seen with diet $\mathrm{A}$. Thus $\mathrm{Hb}$ and PCV were lower and $\mathrm{MCHb}$ was higher, although these differences were not significant $(P>0.05)$. However, the decrease in Rbc and the increase in $\mathrm{MCV}$ in the basal group relative to the group given $20 \mathrm{mg}$ supplemental pteroylmonoglutamic acid $/ \mathrm{kg}$ were significant $(P<0.05$ and $P<0.01$ respectively). Moreover, MCV of the group given a supplement of $2 \mathrm{mg} / \mathrm{kg}$ was also significantly $(P<$ $0.01)$ increased relative to the two higher supplemental levels. Changes in thrombocytes were inconsistent but the proportion of heterophils was increased significantly $(P<0 \cdot 01)$ at the expense of lymphocytes in birds fed on the unsupplemented diet. This group also showed a higher reticulocyte count $(P<0.01)$. These immature cells are shown in Plate 1 (a).

Romanowsky-stained blood films from birds fed on diet A showed cells with many morphological abnormalities compared with those from the control group (Plate $1(b)$ ). These abnormalities persisted in birds fed on diet $B$ alone, although with decreased regularity, and their incidence decreased further as dietary folic acid increased in concentration. A prominent Rbc abnormality was enlarged multi-lobular nuclei, many of which had as many as five distinct lobes (Plate $1(c)$ ). Some cells were spindle-shaped in appearance, containing large, densely-stained, round to oval nuclei and little cytoplasm (Plate $1(d)$ ). Many nuclei were eccentric and occasionally macrocytes were seen (Plate 2). Large numbers of granulocytes also showed hypersegmentation (Plate $3(a)$ ). The blood picture was generally hyperchromic.

\section{Histopathology}

The liver and bone marrow were the only tissues to show pathological change. In birds fed on diet A alone, livers were enlarged, friable and pale, and, microscopically, oedema was present in the portal tracts and parenchyma. There was much damage and separation of the sinusoidal endothelium from the hepatic cords. Pyknotic nuclei were common. Large numbers of inflammatory cells were seen in areas adjacent to the portal tracts and Kupffer cells were prominent. The liver parenchyma was devoid of glycogen after the PAS reaction and reticulin fibres were poorly stained, compared with the control group. 
Folate deficiency in chicks

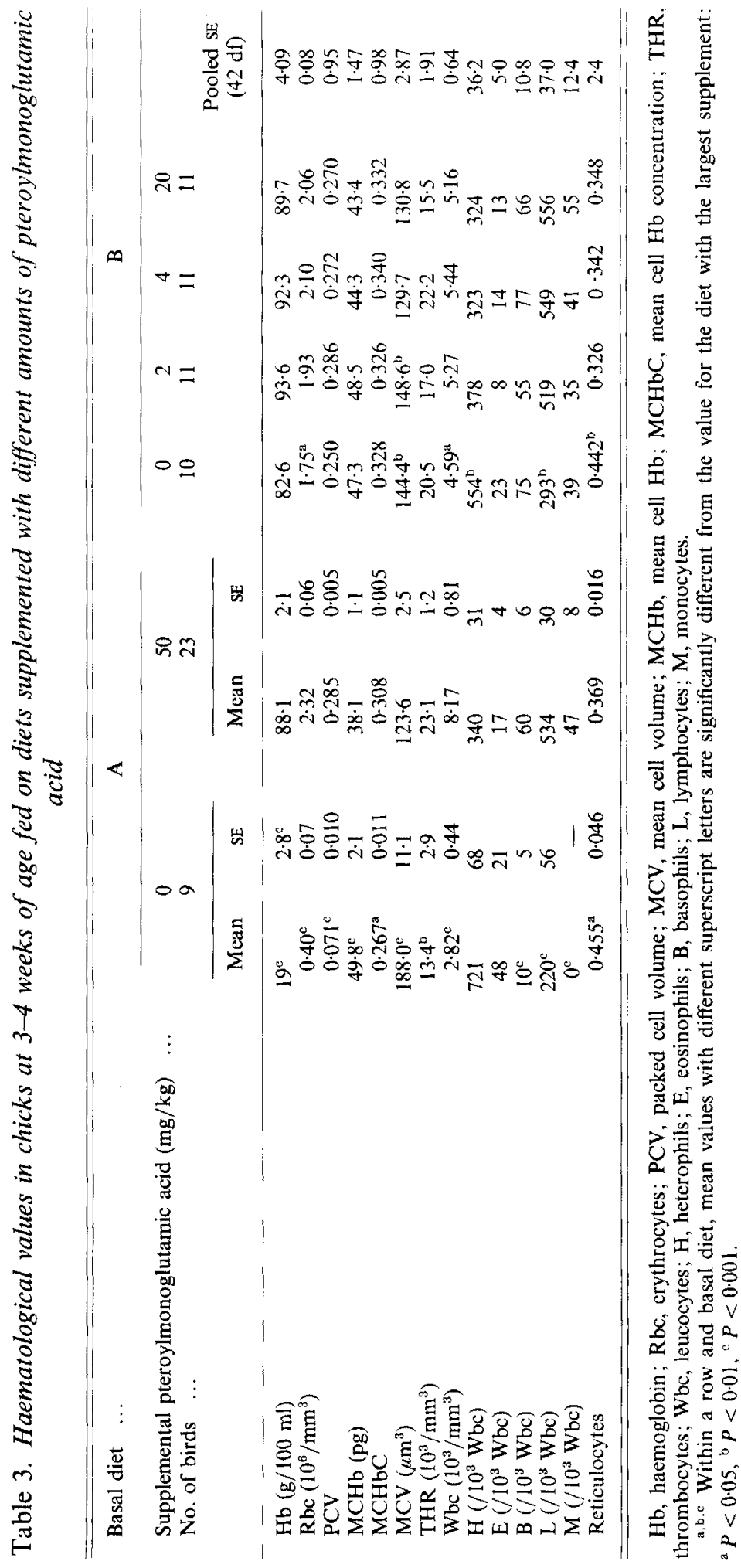


In birds given diets $\mathrm{A}$ and $\mathrm{B}$ without added pteroylmonoglutamic acid, bone-marrow sections and smears revealed many large basophilic erythroid cells, in addition to the normal immature forms that were considered to be megaloblasts (Plate $3(b)$ ). Frequently, there were many cells of the Rbc series displaying various phases of mitosis and macrocytes were common.

\section{Electron microscopy}

The megaloblasts present in the bone marrow were large cells measuring approximately 13.4 (SE 1.90$) \mu \mathrm{m}$ diameter with a range of $10.3-19.0 \mu \mathrm{m}$. They were generally ovoid in appearance with a relatively smooth cytoplasmic membrane containing only a few pseudopodia. The nucleus was also large, occupying approximately two-thirds the volume of the cell. The mean measurement in its greatest dimension was 9.25 (SE 1.15) $\mu \mathrm{m}$ (range $7 \cdot 0-11 \cdot 0 \mu \mathrm{m})$. The nuclei were extremely variable in shape, ranging from round to oval forms with smooth outlines, to those with elongated configurations containing large indentations. Some of these nuclei had appendages of nuclear material or clefts (Plate $3(c)$ ).

The nucleoli measured 3.66 (SE 1.06) $\mu \mathrm{m}$ in their largest dimension with a range of $1.9-5.5 \mu \mathrm{m}$. The majority of cells had only one nucleolus but occasionally two were seen in some cells. A part of the nucleolus was sometimes attached to the nuclear membrane with a wide base. No other heterochromatin areas were seen within the nuclei.

The majority of mitochondria were small, measuring approximately $0.2-0.3 \mu \mathrm{m}$ in diameter, with longer forms measuring up to $2 \cdot 0 \mu \mathrm{m}$. The mean number of mitochondria per cell profile was 42.0 (SE 13.3) with a range of 25-79. In some megaloblasts, mitochondrial degeneration was evident with swelling and loss of cristae formation (Plate $4(a)$ ). Vesicles caused by dilated cisternae of rough endoplasmic reticulum were seen either adjacent to damaged mitochondria or the nuclear membrane (Plate $4(a)$ ). The Golgi apparatus was poorly developed and only occasionally were small electron-dense specific granules present (Plate $4(b)$ ). Infrequently, annulate lamellae and small electron-opaque lipid droplets were seen in some cells. Many of the Rbcs from the folic acid-deficient birds were abnormal in shape with much vacuolation occurring in the cytoplasm (Plate $4(c)$ ).

Ultrastructurally, the hepatocytes in the livers of folate-deficient birds had generally a decreased electron density compared with those from the control group. The nuclei were of normal appearance but a prominent cytoplasmic feature was a granularity present in many mitochondria (Plate $4(d)$ ). Although their size had not altered, the mitochondria frequently had a leached appearance and often the cristae were poorly organized or very indistinct. Many of these mitochondria were associated with dense osmiophilic rods which were usually seen residing between mitochondria (Plate $5(a)$ ) but occasionally within the organelles (Plate $5(b)$ ). Frequently the structures altered the shapes of the mitochondria and sometimes they extended beyond the limits of the mitochondrial membranes. The rods occurred in a variety of sectional planes and the longest encountered measured approximately $4.2 \mu \mathrm{m}$. In some instances the rods displayed a linear crystalline substructure (Plate $5(c)$ ) with a mean repeat pattern measurement of $15 \mathrm{~nm}$. There appeared to be an increase in peroxisomes but no glycogen particles or rosettes were seen in the hepatocytes of deficient birds.

\section{DISCUSSION}

The results of the present investigation confirm that folate deficiency causes hyperchromic macrocytic anaemia in young chickens. The birds fed on the basal diet A were severely deficient, as judged by growth rate, plasma folate concentration and mortality. They 
showed greatly decreased Rbc numbers and total $\mathrm{Hb}$ but increased $\mathrm{MCHb}$ and $\mathrm{MCV}$, characteristic of macrocytosis. These characteristics, together with thrombocytopenia and an increased proportion of heterophils relative to lymphocytes, have already been reported in folate-deficient chicks (Hogan \& Parrott, 1940; Campbell et al. 1945).

Other haematological abnormalities observed in the present study included leucopenia, raised reticulocyte numbers, abnormally shaped $\mathrm{Rbc}$ nuclei, numerous mitoses, hypersegmentation of granulocyte nuclei and the presence of megaloblasts in bone marrow. These numerical and morphological changes seen in blood and bone-marrow cells are similar to those reported previously in human and other mammalian folate deficiencies (Bessis, 1973; Schalm et al. 1975; Wintrobe et al. 1981; Zucker-Franklin et al. 1981). However, so far as we are aware, this is the first time megaloblasts have been reported in avian bone marrow. These cells were large with prominent nucleoli, nuclear clefts and numerous mitochondria, many of which appeared damaged. Degeneration of mitochondria has been described previously in human megaloblasts (Ito et al. 1964; Wickramasinghe \& Bush, 1977; Zucker-Franklin et al. 1981). It has been suggested that most of these degenerative changes lead to death of the affected cells and consequent phagocytosis by bone-marrow macrophages (Zucker-Franklin et al. 1981).

The structural changes seen in livers from folate-deficient birds may be related to the altered liver metabolism seen in folate deficiency diseases in man (Wintrobe et al. 1981). The presence of inter- and intramitochondrial crystalline structures may be important in understanding the involvement of these organelles in stresses induced by dietary deficiencies. Crystalline structures with repeat pattern measurements from 8 to $15 \mathrm{~nm}$ have been reported in hepatocytes from protein-deficient dogs (Ericsson et al. 1966) but appear to be quite different to those observed in the present study. Crystalline inclusions within mitochondria have been widely documented (Ghadially, 1982) but none have resembled the structures reported here. If these crystals affect mitochondrial function, examination of the mitochondrial respiratory-chain enzymes in folate deficiency may be worth further study.

In birds fed on the semi-purified diet B, plasma and serum folate concentrations were low in the unsupplemented group but the growth rate of these birds relative to the supplemented groups did not suggest that they were clinically folate-deficient. However, evidence that these birds were subclinically deficient came from a range of haematological differences that were similar in direction, if not magnitude, to those seen with diet $\mathrm{A}$. $\mathrm{Hb}$ concentration was relatively normal, but $\mathrm{Rbc}$ and reticulocyte numbers and MCV all showed significant changes. The proportion of heterophils in relation to lymphocytes was also greatly changed. These abnormalities responded to increasing levels of dietary pteroylmonoglutamic acid but a supplemental level between 2 and $4 \mathrm{mg} / \mathrm{kg}$ was needed for all responses to reach a plateau. This contrasts with the chick growth requirement estimated by the (US) National Research Council (1984) to be $0.55 \mathrm{mg} / \mathrm{kg}$.

Morphological abnormalities characteristic of folate deficiency were also seen in birds fed on unsupplemented diet B. Typical of these were abnormally-shaped Rbc nuclei, mitoses, hypersegmentation of granulocyte nuclei and the presence of megaloblasts in bone marrow. The similarity of the pathological changes seen in birds fed on basal diets $A$ and $\mathrm{B}$ confirms that the more extreme changes seen with diet $\mathrm{A}$ were attributable to folate deficiency per se rather than to depressed growth and feed intake.

Anaemias of different types can be caused by deficiencies of several vitamins. Macrocytic anaemia is brought about by defective DNA synthesis and inadequacies in pathways involving cobalamin or folate are the most common and best documented causes. Ultrastructurally, the abnormalities caused by deficiencies of these two vitamins in humans are very similar (Wickramasinghe $\&$ Bush, 1977). The present studies show the wide range 
of haematological and morphological abnormalities of overt folate deficiency in chicks. If cobalamin deficiency can be ruled out, the presence of megaloblastic macrocytosis and elevated reticulocyte number and heterophil:lymphocyte ratio may also be useful criteria of subclinical folate deficiency.

The authors thank F. Hoffmann-La Roche \& Co, Basle, for financial assistance.

\section{REFERENCES}

Bessis, M. (1973). Living Blood Cells and their Ultrastructure, pp. 252-260. Berlin: Springer-Verlag.

Campbell, C. J., McCabe, M. M., Brown, R. A. \& Emmett, A. D. (1945). American Journal of Physiology 144, 348-354

Coates, V. \& March, B. E. (1966). Poultry Science 45, 1302-1305.

Ericsson, J. L. E., Orrenius, S. \& Holm, I. (1966). Experimental and Molecular Pathology 5, 329-349.

Ghadially, G. N. (1982). Ultrastructural Pathology of the Cell and Matrix, 2nd ed., pp. 240-245. London: Butterworths.

Hogan, A. G. \& Parrott, E. M. (1940). Journal of Biological Chemistry 132, 507-517.

Ito, K., Ito, N., Sato, S. \& Katsunuma, H. (1964). Acta Haematologica Japonica 27, 436-442.

Maxwell, M. H. (1978). Medical Laboratory Sciences 35, 401-403.

Maxwell, M. H. (1981). Research in Veterinary Science 30, 233-238

National Research Council (1984). Nutrient Requirements of Poultry, 8th ed. Washington DC: National Academy Press.

Schalm, O. W., Jain, H. C. \& Carroll, E. J. (1975). Veterinary Hematology, 3rd ed. Philadelphia: Lea \& Febiger.

Waxman, S. Schreiber, C. (1980). Methods in Enzymology 6E, 468-483.

Wickramasinghe, S. N. \& Bush, V. (1977). Acta Haematologica 57, 1-14.

Wintrobe, M. M., Lea, G. R., Boggs, D. R., Bithell, T. C., Foerster, J., Athens, J. W. \& Lukens, J. N. (1981). Clinical Hematology, 8th ed. pp. 151, 559-597, 617-643. Philadelphia: Lea and Febiger.

Zucker-Franklin, D., Greaves, M. F., Grossi, C. E. \& Marmont, A. M. (1981). Atlas of Blood Cells: Function and Pathology, vol. 1, pp. 75-82. Milan, Italy: Edi. Ermes.

\section{EXPLANATION OF PLATES}

Plate 1. Photomicrographs of chick blood cells in folate deficiency. (a) Reticulocytes (arrows) from bird fed on folate-deficient diet B (brilliant cresyl blue stain, $\times 1120$ ), (b) normal erythrocyte from bird fed on diet A supplemented with $50 \mathrm{mg}$ pteroylmonoglutamic acid $/ \mathrm{kg}$ (May Grunwald-Giemsa stain, $\times 1500$ ), $(c)$ erythrocyte from a bird fed on folate-deficient diet B showing hypersegmentation (May Grunwald-Giemsa stain, $\times 3000$ ), (d) spindle-shaped erythrocytes (arrows) and others with eccentric nuclei $(\boldsymbol{\Lambda})$ from a bird fed on folate-deficient diet A (May Grunwald-Giemsa stain, $\times 1500$ ).

Plate 2. Photomicrographs of macrocytes from chicks fed on folate-deficient diet B (May Grunwald-Giemsa stain, $\times 1120$ ).

Plate 3. Photomicrographs of folate deficiency in chicks. (a) Eosinophil showing hypersegmentation of the nucleus from a bird fed on folate-deficient diet A (May Grunwald-Giemsa stain, $\times 3000$ ), $(b)$ megaloblasts (arrows) from a bird fed on folate-deficient diet A (May Grunwald-Giemsa stain of bone marrow smear, $\times 1120$ ), (c) electron micrograph of megaloblast in bone marrow from a bird fed on folate-deficient diet A, showing large nucleus $(\mathrm{N})$, nuclear cleft (arrow), prominent nucleolus $(\mathrm{Nu})$ and cytoplasm containing many small mitochondria $(\mathrm{M})$, some containing lipid droplets (LD) $(\times 7610)$.

Plate 4. Electronmicrographs of folate deficiency in chicks. (a) Megaloblast in bone marrow from a bird fed on folate-deficient diet A showing degenerating mitochondria $(\mathrm{M})$ and vesicular damage (arrows) $(\times 7610),(b)$ poor development of the Golgi apparatus (GA) and specific electron-dense granules $(G)(\times 10150)$, (c) abnormallyshaped erythrocytes from a bird fed on folate-deficient diet $B$ showing vacuolation of the cytoplasm (arrows) ( $X$ 4370), (d) liver from a bird fed on folate-deficient diet A showing mitochondria (M) with an indistinct granular appearance $(\times 5000)$.

Plate 5. Electronmicrographs of liver mitochondria from folate-deficient chicks fed on diet A showing electrondense osmiophilic rods. (a) Rod wedged between two mitochondria whose membranes (arrows) immediately adjacent to the rod are clearly visible $(\times 38880),(b)$ a rod appearing within the matrix of the organelle $(\times 29160)$, (c) a rod showing a substructure with a repeat pattern of $15 \mathrm{~nm}$ (arrows) between two mitochondria $(\times 48600)$. 
British Journal of Nutrition, Vol. 59, No. I

Plate $1 a, b$
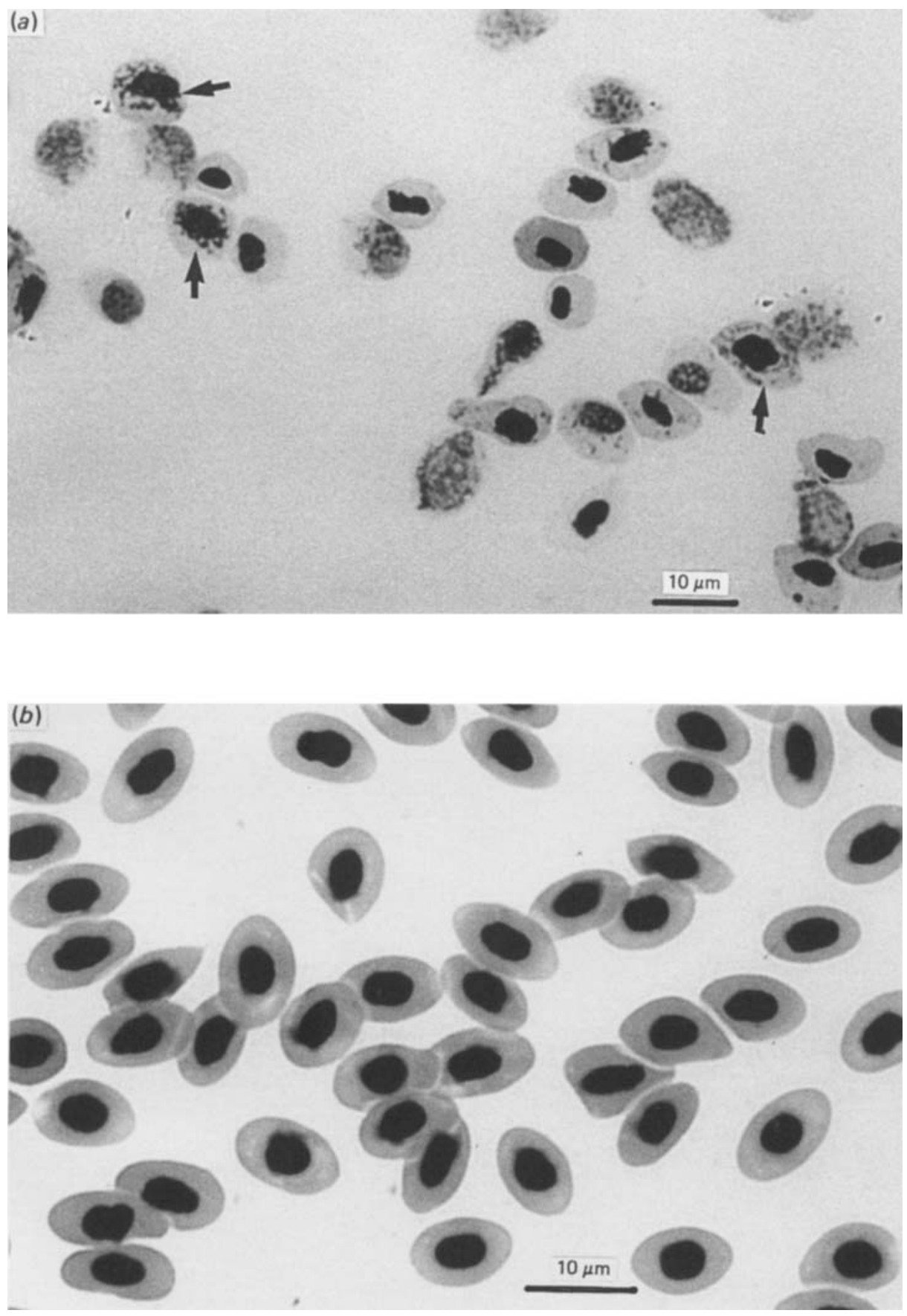

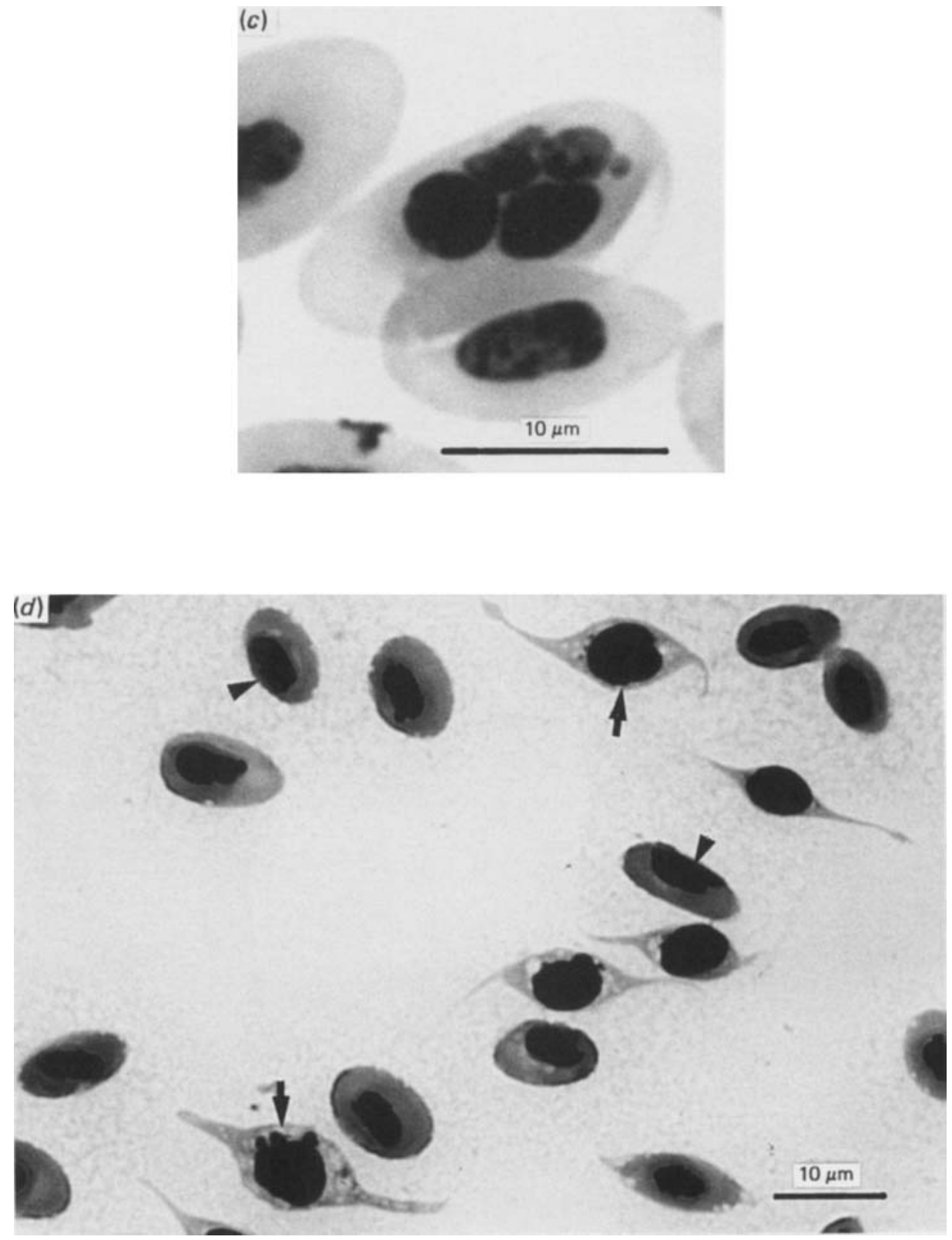

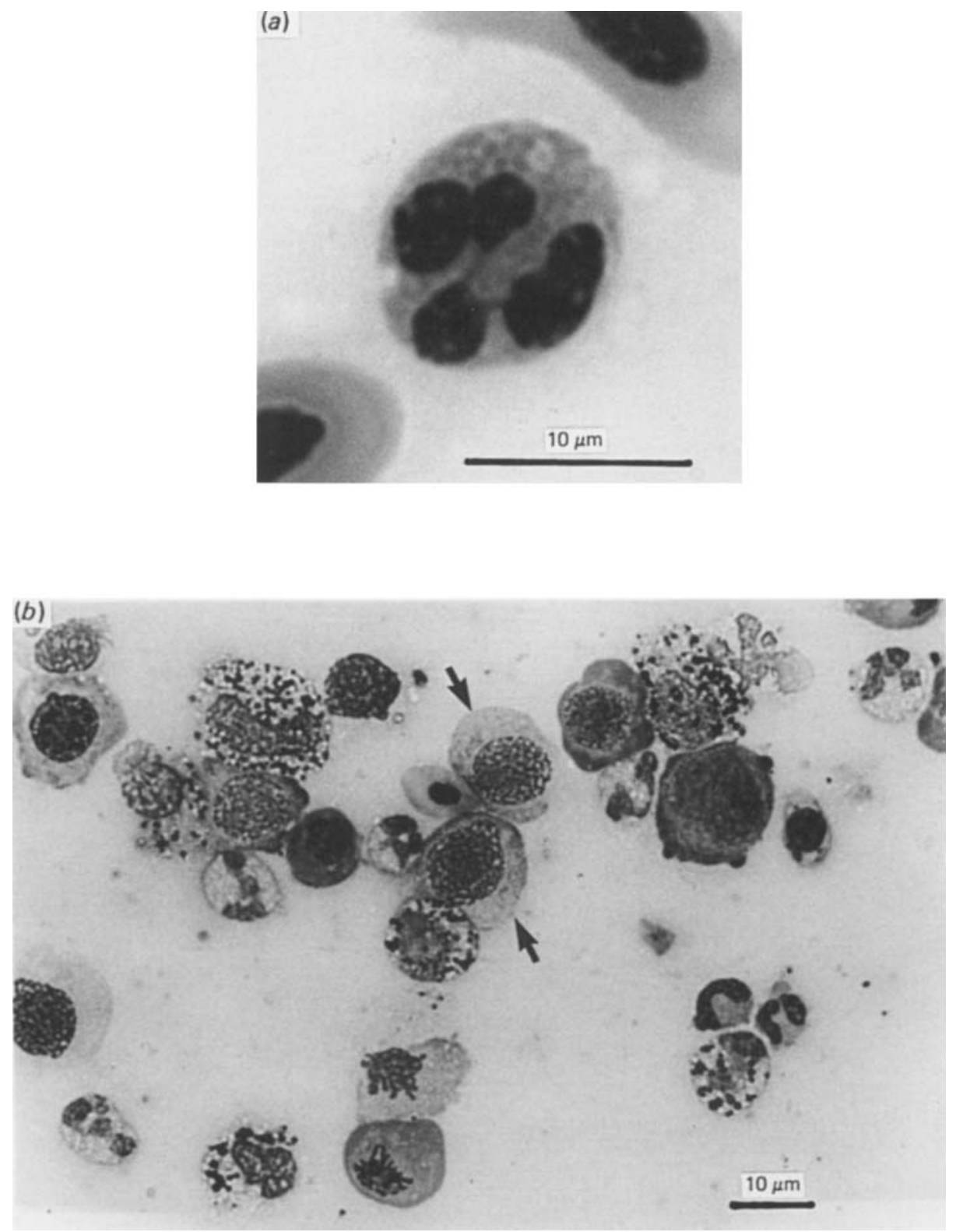

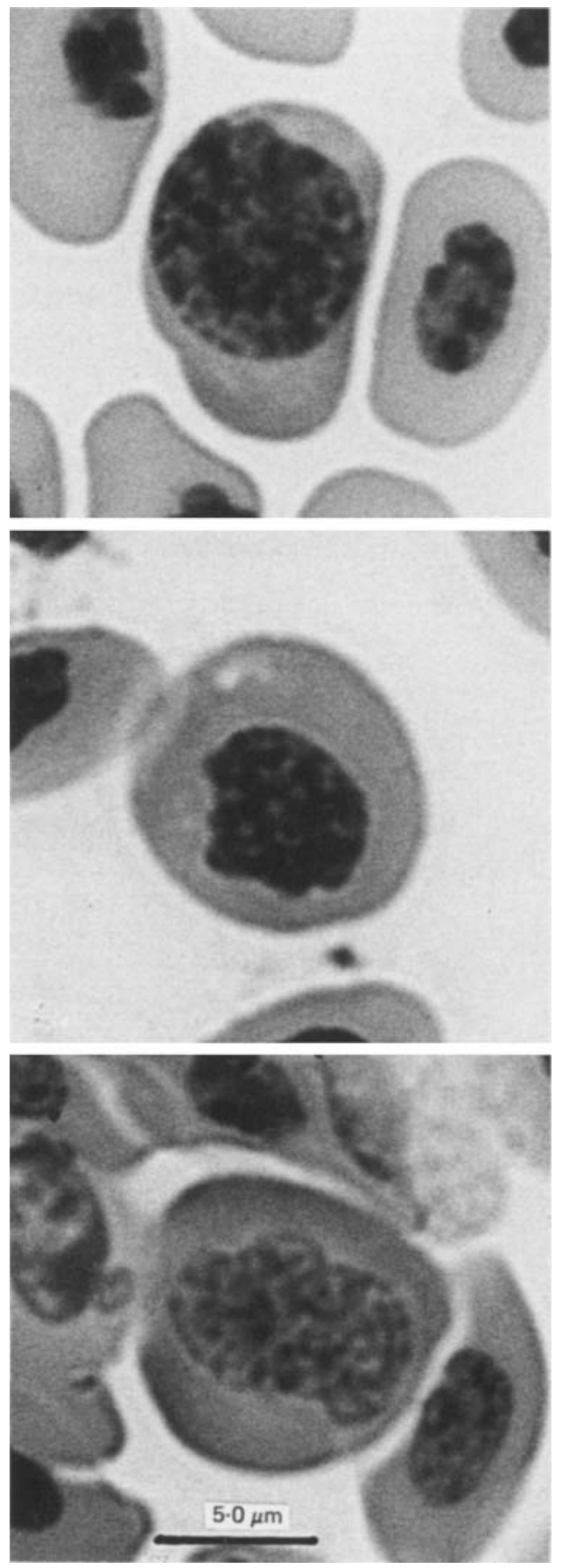
British Journal of Nutrition, Vol. 59, No. 1

Plate $3 c$

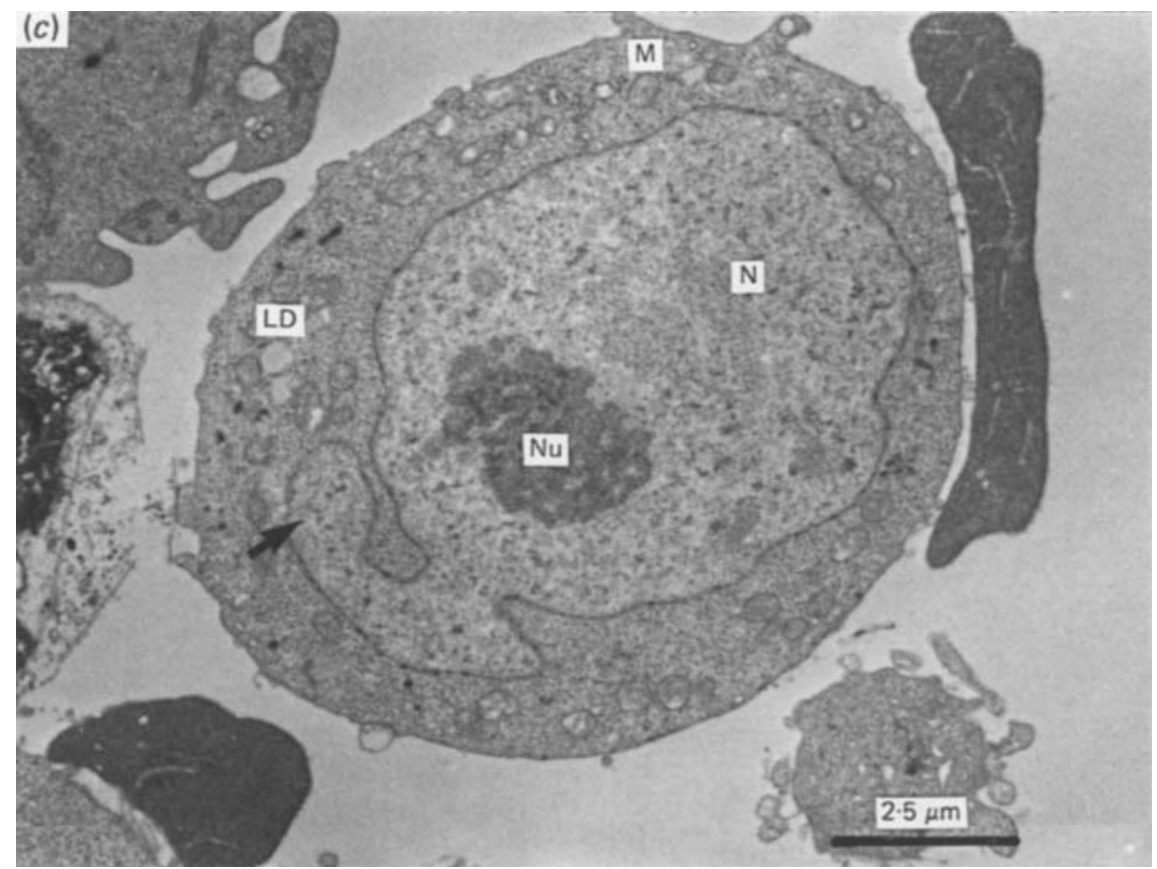



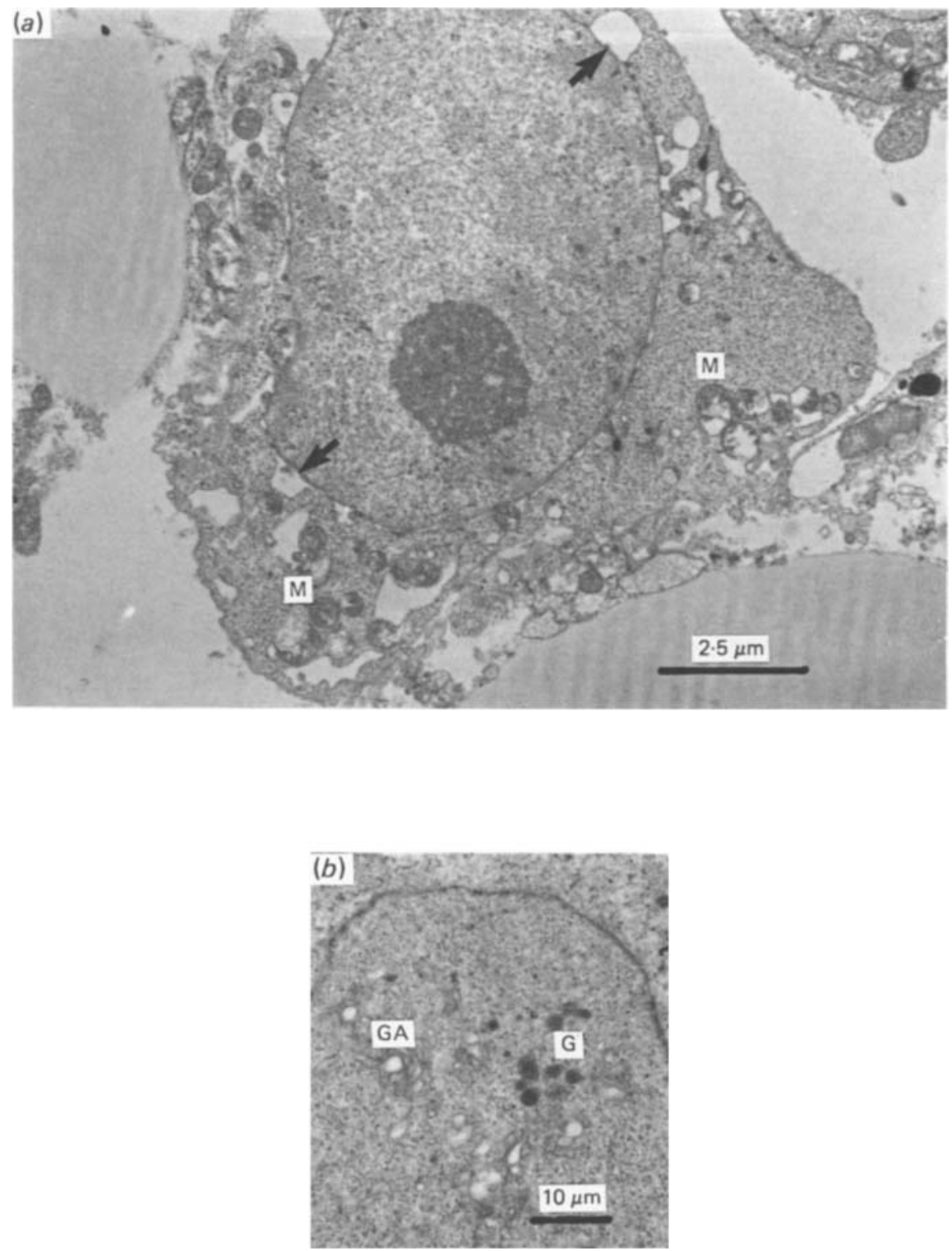
British Journal of Nutrition, Vol. 59, No. 1

Plate $4 c, d$
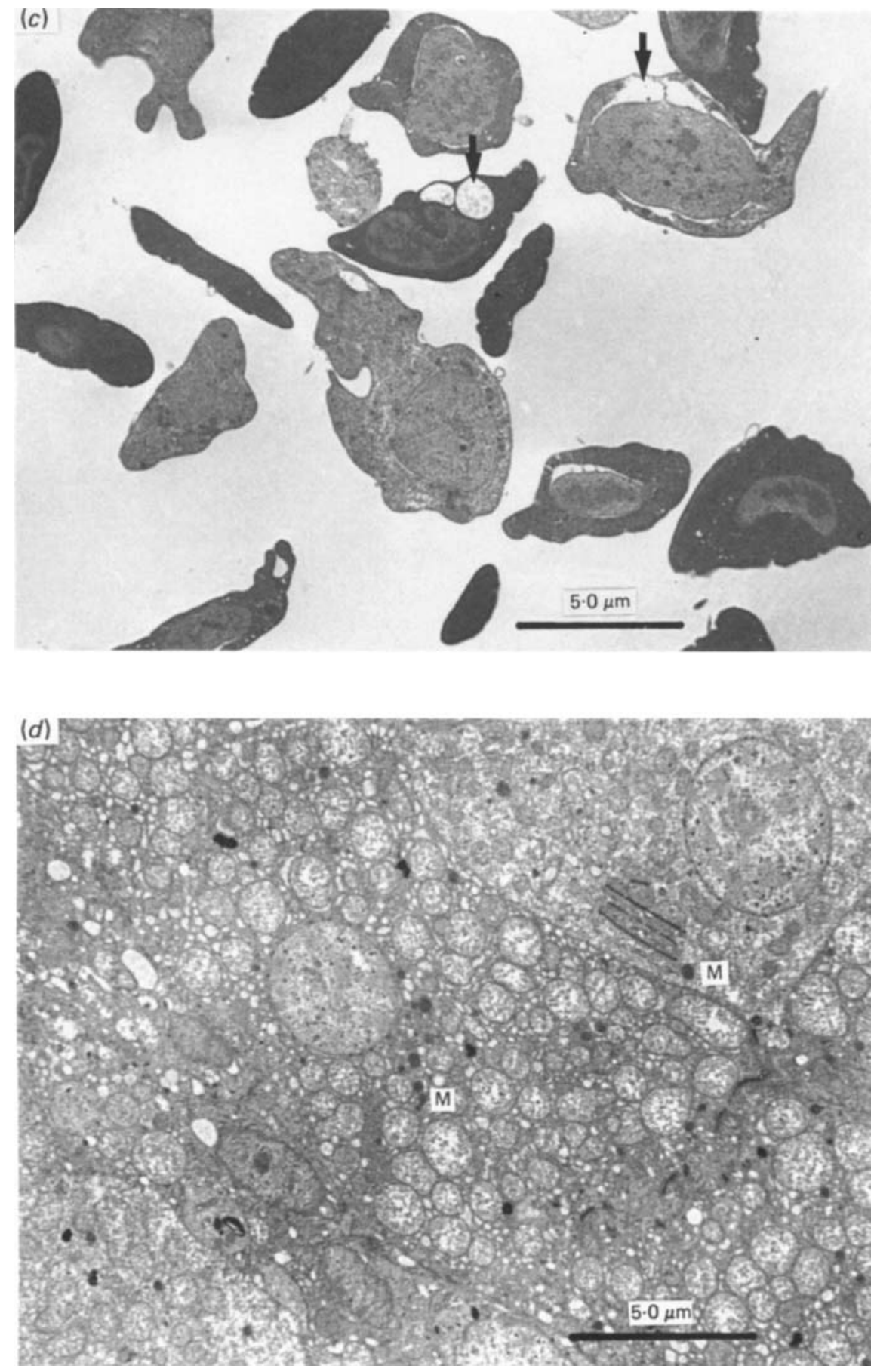

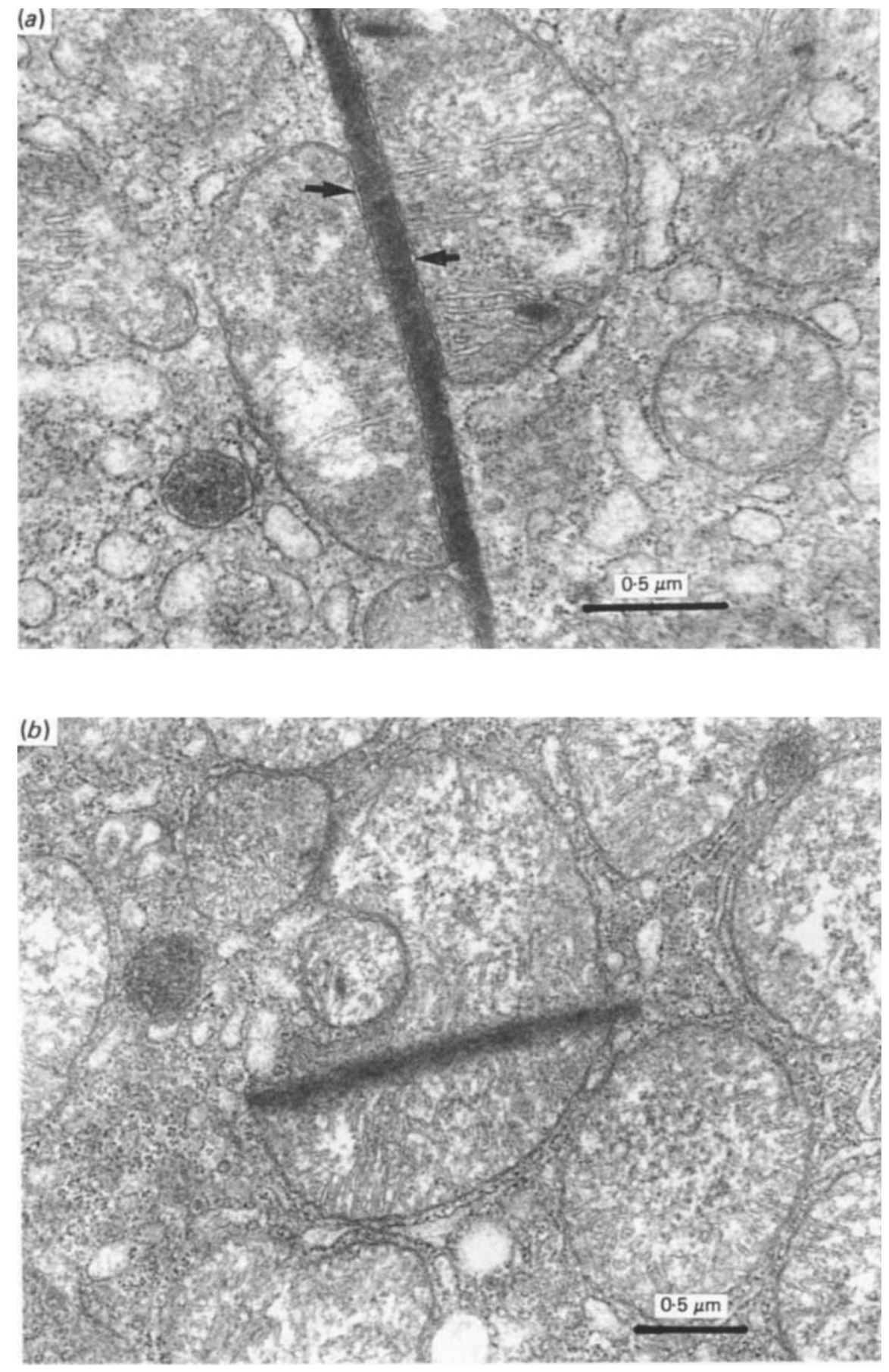
British Journal of Nutrition, Vol. 59, No. 1

Plate $5 c$

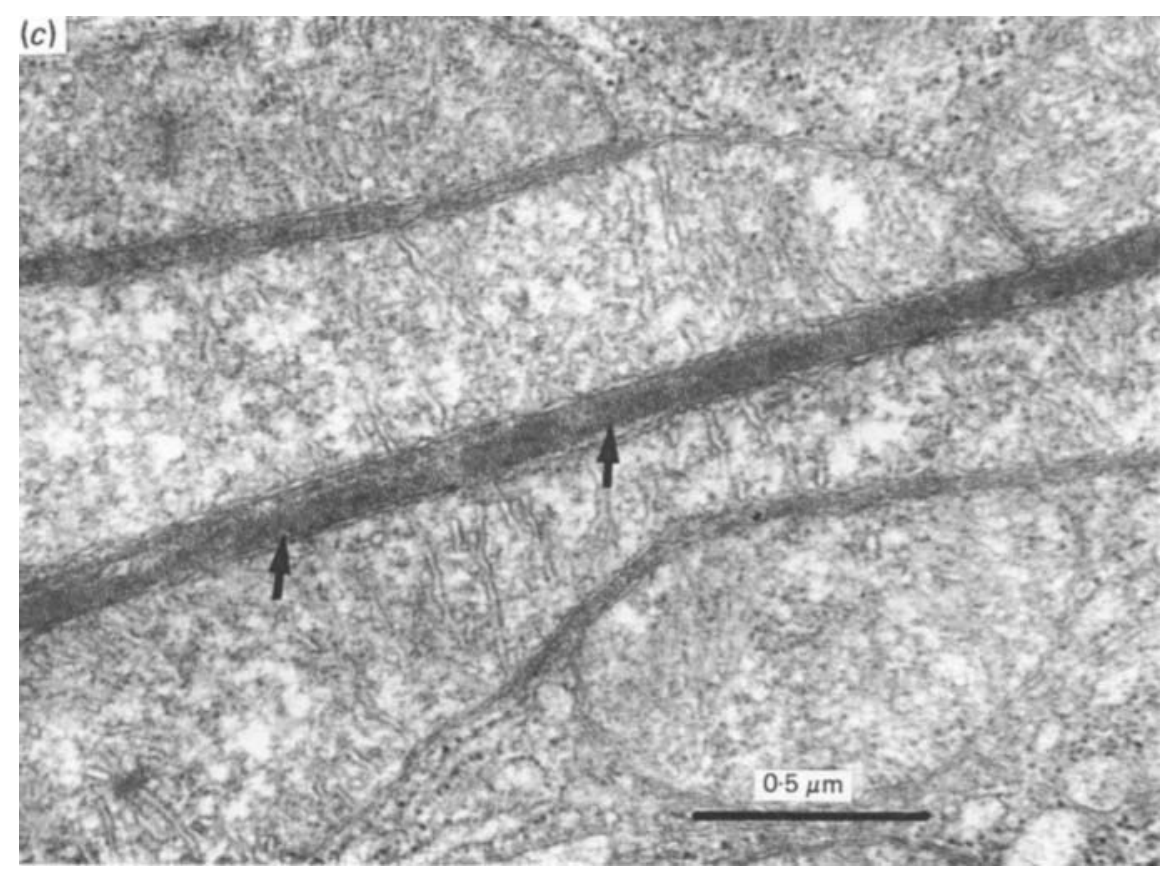

